\title{
A BIBLIOTECA NA PROVÍNCIA DE MINAS GERAIS
}

\section{LA BIBLIOTECA EN LA PROVINCIA DE MINAS GERAIS}

\author{
Nayara Célia Ribeiro Souza Nolasco* \\ Renato Pinto Venâncio**
}

\section{RESUMO}

Introdução: Com a vinda da Família Real e da Corte portuguesa para o Brasil, além do crescimento do hábito de ler e da venda de livros, houve também a criação de instituições, como de biblioteca pública, teatro, imprensa e academias literárias e científicas. Mais especificamente em Minas Gerais, no século XIX, houve na capital da província a criação de bibliotecas.

Objetivo: Baseando-se em um estudo feito por Luiz Antonio Gonçalves da Silva (2010) sobre as bibliotecas brasileiras vistas pelos viajantes no século XIX, pretende-se com este artigo apresentar informações sobre as bibliotecas encontradas em Minas Gerais nesse período.

Metodologia: A metodologia se dá por meio da análise documental mediante leitura, análise e interpretação de periódicos mineiros disponíveis na Hemeroteca Digital Brasileira.

Resultados: Fragmentos que fazem alusão à biblioteca em Minas Gerais foram identificados nos periódicos "O Universal", "O Astro de Minas", "Abelha do Itaculumy", constituindo elementos importantes para constatação do objetivo proposto.

Conclusão: Foi possível constatar que em Minas Gerais houve bibliotecas particulares, públicas, escolares e acadêmicas, sociedades literárias e gabinetes de leitura.

Palavras-chave: Biblioteca. Minas Gerais. Século XIX.

\section{INTRODUÇÃO}

Com a vinda da Família Real e da Corte portuguesa para o Brasil, o hábito de ler e a venda de livros cresceram de forma considerável (MORAES, 2006). Foram criadas por D. João instituições, como, por * Mestre em Ciência da Informação pela Universidade Federal de Minas Gerais (UFMG). E-mail: nayaraceliar@yahoo.com.br

** Doutor em História pela Universidade de Paris IV - Sorbonne. Professor na Universidade Federal de Minas Gerais (UFMG). E-mail: rvenancio@eci.ufmg.br

Inf. Inf., Londrina, v. 21, n. 1, p. $448-464$, jan./abr. 2016.

http:www.uel.br/revistas/informacao/ 
exemplo, a biblioteca pública, teatros, imprensa e academias literárias e científicas, a fim de que possibilitassem a ampliação do nível cultural das pessoas da nova sede do Império português. Além de alargar a relação dos brasileiros com a leitura e os livros, a vinda da Família Real foi importante no incentivo à criação de bibliotecas em várias localidades.

O pesquisador Luiz Antonio Gonçalves da Silva (2010) analisou informações deixadas, nos relatos de viajantes, sobre bibliotecas brasileiras visitadas no decorrer do século XIX e como estas foram vistas no período indicado. Após a análise, o referido autor dividiu em seis categorias as bibliotecas encontradas: biblioteca nacional, bibliotecas de ordens religiosas, bibliotecas particulares, bibliotecas públicas, bibliotecas escolares e acadêmicas, e bibliotecas de colônias estrangeiras.

Em sua pesquisa, Silva (2010) observou que, tendo em vista essa tipologia, as bibliotecas que chegaram a ser implantadas na província mineira no século XIX foram as particulares, a biblioteca pública e as bibliotecas escolares e acadêmicas. A seguir, observaremos essas categorias tomando por base a análise de periódicos mineiros disponíveis na Hemeroteca Digital Brasileira.

\section{BIBLIOTECA PARTICULAR}

Segundo Silva (2010), as bibliotecas particulares foram notadas por vários viajantes. Não sem uma parcela de preconceito, naturalistas europeus, em suas viagens pelo interior do Brasil, observaram mestiços detentores de interesses culturais clássicos. Nas proximidades da floresta amazônica, por volta de 1850, Henry Walter Bates registrou:

Um jovem mameluco [...] o escrivão, levou-me à sua casa para mostrar-me a biblioteca [...] era certamente coisa inesperada encontrar uma biblioteca de clássicos numa cabana de taipa e coberta de folhas de palmeiras das margens do Tocantins (BATES,1944, p. 161). 
No entanto, exemplos como esse eram raros. A própria noção de "biblioteca", quando reportada ao ambiente doméstico, dava origem a situações socialmente fronteiriças. Como caracterizar de tal maneira aqueles que possuíam "apenas um livro"?! E se este livro extravasasse o espaço doméstico, circulando pelas ruas nos dias de se frequentar a missa?! Isso parece ter sido frequente entre as mulheres, conforme observou Debret na época da Independência do Brasil:

A mulher honesta [...] conserva fechadas as cortinas, reservando-se a possibilidade de mostrar-se entreabriando-as com as mãos. Uma das suas criadas de quarto marcha ao lado da cadeirinha para carregar a bolsa e o livro de missa e transmitir suas ordens aos outros escravos que acompanham a poucos passos de distância (DEBRET,1940, p. 158, grifo nosso).

Em razão da escravidão, que excluía escravos e seus descendentes livres do ensino formal, e do ambiente rural, no qual residia a maioria da população, os livros e, consequentemente, as bibliotecas eram raros no Brasil do século XIX. Estas, quando existiam, pertenciam, quase sempre, a membros do clero e a profissionais liberais que dependiam de livros em razão de seus respectivos ofícios.

Maria Callcot, em 1823, observou, por exemplo, na residência de um magistrado carioca, a existência de uma dessas bibliotecas:

Fui levada ao escritório e pela primeira vez vi a biblioteca particular de um brasileiro. Como ele é juiz [...] naturalmente a maior parte é de direito, mas também há história e literatura geral. Principalmente francesa, e alguns livros ingleses. Travei conhecimento com diversos autores portugueses [...] (CALLCOT, 1956, p. 258-9).

O mesmo ocorria em Minas Gerais. De acordo com o relato de John Mawe, naturalista inglês, existiam nessa província algumas bibliotecas particulares. Entre 1809 e 1810, ao chegar ao antigo arraial de Tijuco (atual cidade de Diamantina), o referido naturalista hospedouse em uma casa na qual o anfitrião deu-lhe como quarto um cômodo 
que abrigava uma biblioteca. Tratava-se da residência do Intendente dos Diamantes, que: "Teve a bondade de me dar como quarto a sua biblioteca [...]. Ao lado, via-se belo jardim, de perto de três acres, cheio de relva; toda outrora uma lavagem." (MAWE, 1978, p. 158).

Também em Minas Gerais, o cônsul inglês Richard Burton esteve em Mariana, onde conheceu a biblioteca que pertencera ao bispo dom Antônio Ferreira Viçoso. Conhecido como Dom Viçoso, esse eclesiástico chegou ao Brasil em 1819, iniciando seus trabalhos no Colégio do Caraça (MG). Mais tarde, tornou-se o sétimo bispo da diocese de Mariana entre 1844 e 1875.

Cabe, no entanto, questionar se tais bibliotecas particulares, em determinadas circunstâncias, não se tornavam "públicas". Segundo Silva (2010), havia muita confusão entre o poder público e o privado, uma vez que a ausência do Estado, ainda em construção nesse período, deixava nas mãos de particulares os afazeres que deveriam ser responsabilidade do poder público. Dessa forma, era recorrente nos relatos a presença de frequentadores externos em bibliotecas particulares, uma vez que estas eram organizadas por pessoas que as utilizavam em seus ofícios - atividades compartilhadas por clérigos e profissionais liberais, como advogados, médicos e funcionários, além de juízes e magistrados. Essas bibliotecas, portanto, não estavam restritas exclusivamente ao uso particular e tinham como proprietários pessoas ditas cultas, ligadas à elite, que as utilizavam como espaços de socialização. Nesse meio, a existência de livros também era uma reafirmação de status social de seus possuidores.

\section{BIBLIOTECAS PÚBLICAS}

Foram muitas as iniciativas que proporcionaram a criação de bibliotecas públicas nas capitais das províncias do Brasil, no transcorrer do século XIX.

Silva (2010) ressalta o relato de Walsh, viajante que registrou a biblioteca pública de São João del Rei. Trata-se da primeira da província 
de Minas Gerais. Com o nome de Livraria Pública de São João-del Rei, a biblioteca foi criada em 1827 por iniciativa de um importante comerciante e político da cidade. Baptista Caetano de Almeida ofertou seus próprios livros para composição da biblioteca. A figura do bibliotecário também é descrita pelo viajante:

O bibliotecário é um padre mulato, de aparência bastante curiosa - baixo, gordo, com um vasto chapéu colocado de banda e o rosto afundado no peito. Além de bibliotecário, ele é editor do 'Astro de Minas', um jornal de São João fundado fazia um ano (WALSH, 1985 apud SILVA, 2010, p. 81).

Auguste de Saint-Hilaire (1975, p. 73 apud SILVA, 2010, p. 81) também descreveu como era a situação de Vila Rica (atual cidade de Ouro Preto). Em 1817, o viajante notou que na cidade não havia formas de entretenimento para os moradores. Em seu relato, salienta que não havia um passeio público, um café, nenhuma biblioteca, gabinete literário ou centro de reuniões.

No ano de 1867, em relatos de Burton (1983, p. 289 apud SILVA, 2010 , p. 81) sobre sua visita a Diamantina, o viajante também manifesta seu descontentamento ao observar a ausência de bibliotecas, gabinetes literários e livrarias. Outro que se deparou com semelhante realidade foi o viajante Gardner (1975, p. 211 apud SILVA, 2010, p. 81), que esteve na cidade de Diamantina, em 1840. Nesta não havia nem livreiro, nem bibliotecas.

Desde o início da colonização, as bibliotecas de ordens religiosas tentaram preencher a lacuna da escassez da posse de livro por parte de particulares. Essas instituições eclesiásticas foram as que se estabeleceram com maior regularidade. Minas Gerais, contudo, foi prejudicada nesse sentido pela proibição do estabelecimento de ordens religiosas no período colonial. Por outro lado, após a Independência, essas ordens enfrentaram crises em razão do avanço ultramontano liderado pelos bispados, que restringia a autonomia do clero. 
As bibliotecas instituídas por colônias estrangeiras também são relatadas pelos viajantes e destacadas como uma categoria importante. Segundo Silva (2010), essas bibliotecas funcionavam com regularidade e foram mantidas pelas colônias para auxílio aos conterrâneos. Algumas delas funcionavam nos próprios estabelecimentos comerciais mantidos por estrangeiros, conforme afirma Robert Avé-lallemant, em sua viagem ao Rio Grande do Sul: "Na casa do Senhor Karl Kasten tive uma agradabilíssima surpresa: uma perfeita casa comercial européia [...] examinando-se sua loja, seu quarto, sua biblioteca, descobre-se o alemão educado". (AVÉ-LALLEMANT, 1953, p. 280).

\section{A BIBLIOTECA PÚBLICA DE OURO PRETO}

A biblioteca pública da capital teve sua origem na antiga Sociedade Promotora da Instrução Pública e, posteriormente, passou a pertencer à província por doação dessa mesma sociedade.

O dia 25 de março de 1831, data em que se comemorava o aniversário da Constituição Política do Império do Brasil, foi também a data de inauguração da Biblioteca Pública da Imperial Cidade de Ouro Preto. Foi instaurada a biblioteca pública da capital da província às seis horas da tarde, no estabelecimento de número 11 , situado na rua do Ouvidor (VEIGA, 1892), depois de um longo dia de cortejos, salva de artilharia, iluminação dos estabelecimentos públicos e das casas de alguns cidadãos.

\section{OURO-PRETO}

Sexta feira 25 de Março ao amanher uma salva de artilheria anunciou o nascimento do Sol, e esta se repetio á uma, e as 6 horas da tarde. Houve cortejo no Palacio do Governo, a que concorreâo os Officiaes de L. e 2. Linha e alguns Cidadâos. A'noite toda a Cidade se iluminou espontaneamente, sobresahindo a todas as iluminações a da Caza Camara, e dos dous Quarteis de Cavallaria e Infantaria, os quaes se haviâo já illuminado na noite antecedente, bem como as Cazas de alguns Cidadãos.

Nesse mesmo dia 25 ao anoitecer se abrio a Biblioteca Publica, como havia sido annunciado. Houve um 
grande concurso de pessoas assistentes; e se bem que ella não oferece ainda todas aquellas vantagens, que a instrucção publica pode colher de tâo útil estabellecimento, esperamos todavia que para o futuro chegue áquelle gráo de perfeição, que se deseja. Para manutençâo desta Bibliotheca se instituio uma Sociedade, denominada - Sociedade Promotora da Instrucção Publica. Em outro numero daremos conta dos trabalhos da Sociedade tanto na sua primeira, como na 2. reunião. Podemos desde já assegurar que na Bibliotheca serão patentes para quem quiser ler, até certas horas, além dos Livros que nella existem, os Periodicos desta Provincia, com mui poucas excepções, a maior parte dos do Rio de Janeiro, e alguns das outras Provincias.

- Vai-se aproxximando o tempo em que havemos de gozar de algum socego e tranquilidade publica. Approxima-se o mez de Abril em que deve partir para a Corte o sr. João José Lopes Mendes Ribeiro a difructar mudamente os seis mil cruzados, como Deputado por esta Provincia; as pessaos que tem alguma previdencia já calculâo que passado um mez depois da sua partida, gozaremos do tão desejado socego. O sr. João José em qualquer parte que esteja é sempre o mesmo, e tem tal habilidade para enredar tudo sob capa, que ainda mesmo a quatro legoas desta Capital se sente o pezo da sua influencia. Maldita influencia! Até quando durarás? (O UNIVERSAL, 1831).

\section{BIBLIOTECAS ESCOLARES E ACADÊMICAS}

No período colonial, as atividades voltadas para o ensino no Brasil eram majoritariamente administradas pelos jesuítas. As bibliotecas eram mantidas pelos padres em seus colégios a fim de lhes servirem de apoio em seus trabalhos. Com a expulsão dos jesuítas do Brasil em 1759, essa administração foi desarticulada, e as bibliotecas, espalhadas. Diante disso, seguiram-se as aulas de matérias isoladas de forma fragmentada e dispersa. Várias instituições foram fundadas com a chegada da Corte portuguesa em 1808, como relatado anteriormente, e, dentre estas instituições, estavam as de ensino. Dessa forma, foram criadas a Academia Real da Marinha (1808), a Academia Real Militar (1810), a Academia Médica cirúrgica da Bahia (1808) e a Academia Médica cirúrgica do Rio de Janeiro (1809). 
Com a proclamação da Independência em 1822, é promulgada pelo governo imperial a lei de 15 de outubro de 1827, que "manda criar escolas de primeiras letras em todas as cidades, vilas e lugares mais populosos do império." (BRASIL, 1827). Após a independência, foram organizados, em 1827, os cursos jurídicos de Olinda e São Paulo. Quanto à categoria biblioteca escolar e acadêmica, estas tiveram escassos registros.

O século XIX, marcado pela independência e consolidação do Brasil como Estado-nação, amparou-se nas bibliotecas e em outras instituições culturais, tornando-as cruciais no processo de formação da nova identidade brasileira.

\section{SOCIEDADES LITERÁRIAS, GABINETES DE LEITURA}

As sociedades literárias caracterizavam-se por grupos de pessoas que se reuniam a fim de discutir os problemas de seu tempo, tomando como base a leitura precedente de autores clássicos ou contemporâneos. Comumente estavam associadas às bibliotecas, visto que seus acervos serviam de embasamento para as discussões levantadas. Segundo Rosemary Tofani Motta (2000), essas sociedades literárias tinham uma função importante, pois que, ao se constituírem em um fórum de discussões, apresentavam ao público temas de interesse, suprindo, de alguma forma, a ausência de escolas nas localidades.

Foram criadas, no Brasil, entre os séculos XVIII e XIX, academias literárias, científicas, filantrópicas e de cunho político. Na Bahia, em 1724, existiu a Academia Brazilica dos Esquecidos; no Rio de Janeiro, em 1736, havia a Academia dos Felizes, e, em 1752, a Academia dos Seletos; em 1759, na Bahia, existiu a Academia Brazilica dos Acadêmicos Renascidos; no Rio de Janeiro, em 1772, constituiu-se a Academia Científica.

A atuação dessas associações também podia estar associada a fins particulares de caráter político e reformador. Muito temidas, as sociedades literárias possuíam mais poder de penetração no corpo 
social. De modo geral, eram alavancadas por jovens recém-formados nas universidades europeias, cientes dos problemas políticos da América portuguesa e ansiosos por liberdade e independência. Nessas sociedades, discutiam-se temas que estavam em relevância no momento, e, apesar da ausência da imprensa livre e da dificuldade de comunicação, esses lugares serviam como um espaço formador de opinião (MOTTA, 2000).

Com a permissão de D. Pedro I, em 1831, muitas sociedades foram criadas. A Sociedade Defensora da Liberdade e Independência Nacional destacou-se por sua influência política, disseminando o ideal de liberdade e organização social através das filiais espalhadas pelo Brasil. Essas sociedades também se espalharam pela província de Minas Gerais.

Luciano da Silva Moreira (2006), em sua dissertação, organizou em um quadro esquemático as sociedades políticas, literárias e filantrópicas encontradas em Minas no século XIX, que se reproduziram principalmente durante a regência. De acordo com o autor, houve, entre 1823 e 1838, 36 Sociedades, sendo que três delas estavam instaladas em Ouro Preto: Sociedade Literária (1823), Sociedade Promotora da Instrução Pública (1831), Sociedade Defensora do Throno e da Constituição (1837).

\section{AS SOCIEDADES LITERÁRIAS NA CAPITAL DA PROVÍNCIA}

Em Ouro Preto, no início do século XIX, existiram duas sociedades de incentivo à cultura: a Sociedade Literária e a Sociedade Promotora da Instrução Pública, criadas, respectivamente, em 1823 (Primeiro Reinado) e em 1831 (Regência). Segundo Moreira (2006), a Sociedade Literária funcionou entre 1823 e 1825, e escassas são as referências a respeito da associação, entre cujos objetivos estava a difusão da ilustração pública. A fim de colaborar com a propagação das Luzes, a Sociedade Literária dedicava-se à formação de uma biblioteca interna. 
Quinta feira, 15 de dezembro de 1827.

DISCURSO. Que primeira reunião da Meza Adminstrativa da Biblioteca publica desta Villa recitou o seu Director, o Doutor Aureliano de Souza Oliveira Coutinho, oferecendo á mesma hum projecto de Estatutos para ao estabelecimento da Sociedade Philopoly-techica nesta Villa.

Srs. Louvar a força, e a bravura; louvar o poder, a riqueza e a dependência he quazi sempre hum efeito do medo, da ambição, e de huma stulta admiração, e he além disso hum argumento da baixeza daqueles que suffocão com indigno incensso os que erão mais dignos de compaixão e castigo, do que de louvor. Porém tecer o elogio aos benéficos protectores das sciencias e das arte he oferecer-lhes hum incenso puro e sem suspeita, he huma homenagem de vida de justiça a virtude, para a ver aumentar, porque a virtude louvada cresce; e o louvor sincero e verdadeiro he tão poderoso, e tão eficaz, que por sua intervenção o gênio se apura, a alma se eleva e entao se emprehendem magestosos trabalhos desenvolvem-se sublimes meditações, e executao-se árduas empresas.

Será portanto, Srs., hum puro incenso, sera huma devida homenagem, e nem serao mirrados e infructiferos os encômios que com mao prodiga se liberalisarem sobre o benefico Cidadao, que por amor das letras e sciencias, e a custa de sacrifícios pessoaes acaba de offertar ao Publico desta Villa dous tao uteis estabelecimentos, quaes huma Typographia, e huma Biblioteca Publica estabelecimentos devidos sem duvida ao progresso do espirito humano deve sem duvida o seo progresso. Não basta porém, Srs., tao generosa offerta: ella ficaria condemnada ao pó, e ao esquecimento, se o mesmo honrado Cidadao, se todos nós, animados de hum igual zelo pelo progresso. Não basta porém, Srs., tao generosa offerta: ella ficaria condemnada ao pó, e ao esquecimento, se o mesmo honrado Cidadão, se todos nós, animados de hum igual zelo pelo progresso das letras, não cooperássemos de nossa parte, e quanto em nos coubesse para pôr em acçao, e dar alma e vida a estes dous tao uteis como interessantes corpos. He por isso que deslumbrado de minhas apoucadas forças,e grato a honra que me fizesteis de nomerar me vosso Director, eu tomo a de offertar-vos hum projecto de estatutos para a organização de huma sociedade literária único meio que me parece efficaz para a animação, protecçao, e augmento daquelles dous corpos, e com eles do espirito, e amor das letras. Os homens, Srs. Como diz Pope, querem ser ensiandos, porem de modo que não pareça que o são = mem must be tanght, as if yontonght them not = (ensaio sobre critica v. 574); he por tanto sempre o meio indirecto o mais eficaz para

Inf. Inf., Londrina, v. 21, n. 1, p. 448 - 464, jan./abr. 2016. 
obter tal fim; e eu me lisongeio de que este meio se acha empregado em toda a sua extensão na organizaçao da Sociedade ora emprehendida. A sua instituição tem pois por fim trez objetos de nenhum modo indifferentes para propagação das luzes: 1 accender por meio de emulaçao o amortecido espirito de literatura; 2. Obrigar pelo meio indirecto a leitura dos Periodicos Nacionaes, e Estrangeiros, e de outras peças, não so os sócios, mas ainda os que o não sao, os quaes sendo assignantes do nosso periodico mensal, movidos sem duvida da curiosidade serao levados a sua literatura, na qual deverao achar os extractos desses periódicos, e as mais peças nelle inseridas; 3. Finalmente buscar aos dous uteis estabelecimentos das Biblioteca Publica e da Imprensa nesta Villa huma desinteressada e constante administração e protecçao. Exhortar-vos, Srs., para que de vossa parte nao desanimeis nessa protecçao, já por vos começada, seria seguramente fazer ofensa ao vosso Patriotismo, e luzes. Vos sabei que a idade de ourode cada Naçao foi sempre aquella em que as artes e sciencias obtiverao huma decidida protecçao já de seos Principes, e já mesmo de Insituiçoes particulares; sabeis que nehuma Nação pode ser grande e respeitada entre as outras sem que nella foreçaoas artes, e sciencias; sabeis finalmente que os mesmos protectores das artes e sciencias são pagos com usura de suas protecçoes; os elogios dos Sabios, as suas obras sabem grangear-lhes hum nome immortal; o grande Alexandre esmorecia muitas vezes depois de grande victorias porque não havia (dizia elle) hum Homero para Ih'as cantar. E com effeito, seráo baldados todos os esforços da vaidade humana, quando solicita busca immortarlisar seos herores, se hum Poeta, se hum orador sensível, se hum sábio filosofo nao accenderem com a sua voz. As estatuas, as pirâmides, os obeliscos, que tem solidas bases, que parecem eternas, que querem disputar a duraçao com o mesmo tempo, desaparecerao hum dia, bem como o heroe ali representado; o tempo, que tudo destroe , lançando por terra esses marmores farà que 0 viandente nao encontrado jà nemas ruinas desconheça até o lugar do monumento;mas que quão diferente he a sorte do heroe que foi immortalisado pelos elogios dos Sabios! O mausoleo, e o cenothaphio de hum Catao, de hum Aristes já não existem mas as suas acçoes são perpetuadas pelo filosofo de Cheronéa; o lugar em que jaz a urna da Agricola he hoje desconhecido, mas as suas virtudes são eternas em Tacito.

Por estas rasoes pois, Srs. Por esta nobre ambiçao, quando não fosse so pelo vosso decidido patriotismo, e desinteressado amor das letras, he sem duvida que continuareis a cooperar para a elevada e subida 
empresa do nosso estabelecimento literário, he sem duvida que vos prestareis gostosos a quanto vos he marcado nos presentes Estatutos que tenho a honra de vos oferecer, e que espero de vos me fareis a duplicada de aceitar.

Aureliano de Souza e Oliveira Coutinho (AZEVEDO, 1885, p. 266).

A propagação das Luzes era, então, entendida como o governo constitucional. Essa forma de organização política representava a diminuição do ímpeto absolutista do Império, principalmente após a criação do Poder Moderador, por parte de Dom Pedro I. Em outras palavras, a existência de um poder legislativo e judiciário autônomos garantia emancipação e acesso às estruturas de poder por parte das elites regionais. Não por acaso, o jornal de maior duração no período, $O$ Universal, foi fechado em razão de seu apoio à Revolução Liberal de 1842 (ARAUJO, 2007, p. 83).

A Sociedade Literária era auxiliada financeiramente pelo proprietário da Officina Patrícia de Barbosa e Cia. Para a manutenção da Sociedade, doava-se, dentre outros objetos, papéis e livros. Quanto à formação da biblioteca, esta também contava com a colaboração de doadores, como se pode observar na sessão "Correspondencia" do jornal Abelha do Itaculumy.

\section{CORRESPONDENCIA.}

O Diretor da Sociedade Literária desta Imperial Cidade, em nome da mesma Sociedade dirige os mais cordiaes agradecimentos ao Sr. Patritota, que offereceo para augmento da sua Livraria as Obras seguintes - Noticias curiosas, e necessarias sobre o Brasil -Contracto Social de J.J. Rosseau - O Monarcha perfeito. Por esta ocasião em nome da mesma Sociedade se tributão igaues agradecimentos ao R. ${ }^{\mathrm{mo}} \mathrm{Sr}$. José Joaquim Viegas de Menezes pela offerta do Plano da Cidade de Paris, com que a brindou, e se acha para ser observado pelos curiosos, que quiserem. Acceitem pois os mesmos Senhores estas expressões puras de gratidão; ás quaes o Director une as de maior consideração, e affecto, que se preza de lhes consagrar. Ouro Preto 18 de Marços de 1825 (O ASTRO DE MINAS, 1827). 
As sociedades políticas, literárias e filantrópicas eram locais de civilidade que tinham como objetivo as práticas da difusão das Luzes, a filantropia e, acima de tudo, a formação e organização política dos indivíduos (MOREIRA, 2006).

A Sociedade Promotora da Instrução Pública foi criada em Ouro Preto, em 25 de março de 1831, e tinha como propósito inicial manter a biblioteca pública da cidade. Além disso, almejava a publicação de um jornal denominado Jornal da Sociedade Promotora da Instrução pública, no qual veicularia matérias sobre a educação.

A Sociedade Promotora da Instrução Pública, além de realizar ações que tentavam promover as instituições escolares na província, também se preocupou com a formação de bibliotecas. Como se pode observar nas páginas do jornal $O$ Universal, a sociedade organizou uma comissão encarregada de redigir o Estatuto próprio e o de sua biblioteca. Tais iniciativas foram registradas em 1831, na primeira Sessão Preparatória realizada pela Sociedade Promotora da Instrução Pública.

\section{OURO PRETO}

Cumprindo o que prometemos em o $\mathrm{N}$. antecedente daremos conta dos trabalhos da Sociedade Promotora da Instrucção Publica.

$\mathrm{Na}$ sua primeira Sessão Preparatória a a Sociedade nomeou pro aclamação para Presidente ao sr. Desembargador Manuel Ignacio de Mello e Souza e para Secretarios os srs. Francisco de Paula Santos e Herculano Ferreira Pena; e uma Comissão para formar os Estatutos sobre preliminares que offereceo o Cidadão Manoel Soares do Couto, composta do mesmo Cidadão, e dos srs. Desembargador Bernardo Pereira de Vasconcellos, Lucas Antonio de Souza Oliveira e Castro, Francisco de Assis d'Azeredo Coutinho, e José Pedro de Carvalho; e afixou-se para a Installação da Sociedade o dia 27.

Neste dia reunidos os Socios a Comissão apresentou o Projecto dos Estatutos com o seu Parecer, e sendo aquelles aprovados interinamente, a Meza nomeou os Eleitores que devião eleger a nova Meza encarregada do Governo da Sociedade, a qual procedendo na forma dos Estatutos á eleição dos 5 Membros e dous Supplentes, forão nomeados para Membros effectivos os mesmos que compunhão a Meza interina com o sr. 
M.S. do Couto, e J. P. de Carvalho; e para Supplentes os srs. A. R. Fernandes Forbes, e Francisco de Assis de Azeredo Coutinho. Tomando posse a nova Meza o sr. Paula Santos leu um Discurso analogo ao objecto da reunião, depois do que se dissolveo o ajuntamento, a que havia concorrido grande numero de Cidadãos amigos dos progressos da Instrucção Publica, e das Instituições Livres do seu Paiz.

[...] Art. 7. Esta Sociedade se encarrega:

$\S 1$. De ter uma Bibliotheca Publica, na qual poderão ler gratuitamente todas as pessoas, que quiserem uma vez que guardem as regras policiaes estabelecidas pela Administração. A Bibliotheca estará aberta todos os dias cinco horas pelo menos.

$\S 2$. De promover o augmento da mesma Bibliotheca, e de quanto possa contribuir para a difusão das luzes, e consolidação dos Sistema Constitucional.

$\S 3$. De fazer publica um Jornal denominado - Jornal da Sociedade Promotora da Instrucção Publica - que contenha notícias verídicas de todas as Provincias do Imperio, e principalmente do estado, e progressos da Instrucção Publica de Minas, as Extrangeiras, e as doutrinas mais adaptadas á conservação do Sistema Constitucional (ABELHA DO ITACULUMY, 1825).

\section{CONCLUSÃO}

Perante o exposto, é possível inferir que no século XIX, em Minas Gerais, existiram algumas categorias de bibliotecas elencadas por Silva (2010) que foram bibliotecas particulares, públicas, escolares e acadêmicas, as sociedades literárias e gabinetes de leitura. Dentre estas, as que mais se desenvolveram foram as bibliotecas públicas, escolares e acadêmicas, embora existam poucas informações sobre estas últimas.

\section{REFERÊNCIAS}

ABELHA DO ITACULUMY. Ouro Preto, 18 mar. 1825.

ARAÚJO, Maria Marta. Com quantos tolos se faz uma república?: Padre Correia de Almeida e sua sátira ao Brasil oitocentista. Belo Horizonte: UFMG, 2007. 319 p. 
AVÉ-LALLEMANT, Robert. Viagem pelo Sul do Brasil: no Ano de 1858. Rio de Janeiro: INL, 1953. Disponível em: < http://antigo.mcb.org.br/ernMain.asp >. Acesso em: 12 jul. 2014.

AZEVEDO, Manuel Duarte Moreira. Sociedades fundadas no Brasil desde os tempos coloniais até o começo do atual reinado. Revista do Instituto Histórico e Geográfico Brasileiro. Rio de Janeiro, Tomo 48, Parte 1, p. 265-322. 1885.

BATES, Henry Walter. O naturalista no rio Amazonas. São Paulo: Companhia Editora Nacional, 1944. Disponível em:

<http://www.brasiliana.com.br/obras/o-naturalista-no-rio-amazonas>. Acesso em: 7 jul. 2014.

BRASIL. Lei de 15 de outubro de 1827. Disponível em: <http://www.planalto.gov.br/ccivil_03/leis/LIM/LIM-15-10-1827.htm>. Acesso em: 7 jul. 2014.

CALLCOT, Maria Dundas Graham Lady. Diário de uma viagem ao Brasil e de uma estada nesse país durante parte dos anos de 1821, 1822, 1823. São Paulo: Companhia Editora Nacional, 1956. p. 258-9. Disponível em: <http://antigo.mcb.org.br/ernMain.asp>. Acesso em: 7 jul. 2014.

DEBRET, Jean-Baptiste. Viagem pitoresca e histórica ao Brasil (1816-1839). 2. ed. São Paulo: Martins, 1940.

MAWE, John. Viagens ao interior do Brasil (1807-1810). São Paulo: EDUSP, 1978. p. 158. Disponível em:

<http://antigo.mcb.org.br/ernMain.asp>. Acesso em: 9 jul. 2014.

MORAES, Rubens Borbae. Livros e bibliotecas no Brasil colonial. 2. ed. Brasília: Brinquet de Lemos, 2006.

MOREIRA, Luciano da Silva. Imprensa e política: espaço público e culta política na província de Minas Gerais 1828-1842. 2006. 270 f. Dissertação (Mestrado em História) - Faculdade de Filosofia e Ciências Humanas, Universidade Federal de Minas Gerais, Belo Horizonte, 2006. Disponível em: <http://hdl.handle.net/1843/VCSA-6X6LY9>. Acesso em: 14 jul. 2014.

MOTTA, Rosemary Tofani. Baptista Caetano de Almeida: um mecenas do projeto civilizatório em São João dél-Rei no início do século XIX - a biblioteca, a imprensa e a sociedade literária. 2000. 17 f. Dissertação (Mestrado em Ciência da Informação) - Escola de Biblioteconomia, Universidade Federal de Minas Gerais, Belo Horizonte, 2000.

O ASTRO DE MINAS. São João del Rei, dez. 1827.

O UNIVERSAL. Ouro Preto, mar. 1831. 
SILVA, Luiz Antonio Gonçalves. Bibliotecas brasileiras vistas pelos viajantes no século XIX. Ciência da Informação, Brasília, v. 39, n. 1, p. 67-87, jan./abr. 2010. Disponível em: <http://revista.ibict.br/ciinf /indexphp/ciinf/article/viewArticle/1773>. Acesso em: 9 jul. 2014.

VEIGA, José Pedro Xavier. A imprensa em Minas Gerais (1807-1897). Ouro Preto: Imprensa Oficial de Minas Gerais, 1892.

\title{
Title
}

The library in the province of Minas Gerais

\begin{abstract}
Introduction: With the arrival of the royal family and the Portuguese Court to Brazil, besides the growth habit of reading and selling books there was also the creation of institutions to the public library, theater, media and literary and scientific academies. More specifically Minas Gerais in the nineteenth century was the capital of the province creating libraries.

Objectives: Based on a study by Luiz Antonio Gonçalves da Silva (2010) on Brazilian libraries seen by travelers in the nineteenth century it is intended with this paper to present information about the libraries found in Minas Gerais in this period.

Methodology: The methodology is through documentary analysis through reading, analysis and interpretation of miners periodicals available in Hemeroteca Digital Brasileira.

Results: Fragments alluding to the library in Minas Gerais were identified in the periodic " O Universal ", "O Astro de Minas", Abelha do Itaculumy " constitute important elements for determining the proposed objective

Conclusions: Where it was established that there were Minas Gerais in private, public, school and academic libraries, literary societies and reading consultants.
\end{abstract}

Keyword: Library. Minas Gerais. Nineteenth century.

\section{Titulo}

La biblioteca en la provincia de Minas Gerais

\section{Resumen}

Introducción: Con la llegada de la familia real y la corte portuguesa a Brasil, además del hábito de crecimiento de la lectura y la venta de libros había también la creación de instituciones para la biblioteca pública, el teatro, los medios de comunicación y las academias literarias y científicas. Más específicamente Minas Gerais en el siglo XIX fue la capital de la provincia la creación de bibliotecas.

Objectivos: En base a un estudio realizado por Luiz Antonio Gonçalves da Silva (2010) sobre las bibliotecas brasileñas vistos por los viajeros en el siglo 
XIX que se pretende con este trabajo para presentar información sobre las bibliotecas que se encuentran en las Minas Gerais en este periodo.

Metodología: La metodología es a través del análisis documental a través de la lectura, el análisis y la interpretación de las publicaciones periódicas de los mineros disponibles en Hemeroteca Digital Brasileira.

Resultados: Los fragmentos que aluden a la biblioteca en Minas Gerais se identificaron en el periódico " O Universal ", " O Astro de Minas ", "Abelha do Itaculumy " son elementos importantes para la determinación del objetivo propuesto

Conclusión: Donde se estableció que había Minas Gerais en privado, público, escuela y las bibliotecas académicas, sociedades literarias y consultores de lectura.

Palabras clave: Biblioteca. Minas Gerais. Del siglo XIX.

Recebido em: 23.07.2014

Aceito em: 09.04.2016 